\title{
Bioequivalence Study of Troxipide Tablet Formulations
}

\section{Dewan Bhupesh*, Sahu Navajit}

\author{
Zuventus Healthcare Ltd., 5119 ‘D’ Wing, Oberoi Garden Estate, Chandivilli, Mumbai 400072 , India
}

\begin{abstract}
Troxipide is a novel gastro protective agent with antiulcer, anti-inflammatory and mucus secreting properties. This bioequivalence study was carried out to determine the pharmacokinetic profile of troxipide in plasma in an open label, comparative, randomized, two way cross over design involving two treatments and two periods with one week washout period in 28 healthy male subjects.
\end{abstract}

Blood samples were collected at intervals up to 28 hours, as per the approved protocol. Plasma concentrations of troxipide were analyzed by high performance liquid chromatography (HPLC) and noncompartmental method was used for pharmacokinetic analysis. The mean $( \pm$ S.D. $)$ values of the pharmacokinetic parameters (test vs. reference) were $\mathrm{C}_{\max }\left(1052.47 \pm 254.41\right.$ vs. $\left.1039.10 \pm 301.54 \mathrm{ng} \mathrm{ml}^{-1}\right)$, AUC $_{(0-t)}\left(8737.48 \pm 1545.24\right.$ vs. $8850.04 \pm 1892.63 \mathrm{ng} \mathrm{h} \mathrm{ml}^{-}$ $\left.{ }^{1}\right), \mathrm{AUC}_{(0-\infty)}(9622.12 \pm 1692.57$ vs. $9695.02 \pm 2133.95 \mathrm{ng} \mathrm{h}$ $\left.\mathrm{ml}^{-1}\right)$, and $\mathrm{t}_{1 / 2}(7.44 \pm 1.85$ vs. $7.24 \pm 2.10 \mathrm{~h})$. There were no statistically significant differences between $\mathrm{C}_{\max }, \mathrm{AUC}_{(0-\mathrm{t})}$ and $\mathrm{AUC}_{(0-\infty)}$ and their log transformed data $(\mathrm{p}>0.05)$ for the test and reference formulations. The $90 \%$ of confidence intervals (C.I.s) for the test/reference ratio of mean $\mathrm{C}_{\max }$, $\mathrm{AUC}_{(0-\mathrm{t})}$, and $\mathrm{AUC}_{(0-\infty)}$ were within the acceptable range of 80.00 to 125.00 . The mean ( \pm S.D. ) times to maximal plasma concentration $\left(\mathrm{t}_{\max }\right)$ of troxipide were $3.04 \pm 0.93$ vs. $3.07 \pm 1.39 \mathrm{~h}$ for the test and the reference formulations respectively. Both the formulations were well tolerated.

In conclusion, the two formulations were bioequivalent and may be used interchangeably.

Keywords: Troxipide; Pharmacokinetics; Bioequivalence; High performance liquid chromatography

\section{Introduction}

Troxipide is a novel gastric mucosal protective agent with chemical formula 3, 4, 5-trimethoxy-N-(3-piperidyl) benzamide (Figure 1). Antiulcer effect of troxipide is due to increase in gastric mucosal blood flow, mucus secretion (Mine et al., 1991), glycoprotein excretion in the gastric mucosa and inhibition of inflammatory responses and mucosal injury mediated by neutrophils (Kusugami et al., 2000). It increases gastric mucosal prostaglandin (PG) levels as evidenced in animal studies. This finding is of interest because endogenous $\mathrm{PG} \mathrm{E}_{2}$ plays a regulatory role in gastrointestinal function. Moreover PG $\mathrm{E}_{2}, \mathrm{PG} \mathrm{I}_{2}$ and PG D promote gastric ulcer healing (Mine et al., 1991). Troxipide promotes ulcer repair by increasing collagen regeneration of the ulcer base (Prescribing information, Aplace $^{\circledR}, 2010$ ) and causes healing of peptic ulcer (Hyeoyun, 1989).

Production of reactive oxygen radicals is believed to be one of pathogenic factors involved in neutrophil induced gastric mucosal injury (Kusugami et al., 2000). Troxipide can prevent the generation of oxygen free radicals, thereby protecting the gastric mucosa (Momo et al., 1994). Troxipide is also found to have anti-inflammatory properties and inhibits chemotactic migration of human neutrophils to the inflammatory sites (Kusugami et al., 2000).

Troxipide has no effect on gastric acid output (Mine et al., 1991) and its action is independent of the gastric $\mathrm{pH}$ (Wang et alЦ, 1993).

Troxipide is available in Japan for the treatment of gastritis and gastric ulcers for a number of years. This product is not available in Europe, USA or India. The objective of the present study was to compare the pharmacokinetic profiles of troxipide formulation manufactured by Emcure Pharmaceuticals Ltd., India, with the commercially available Aplace®, of Kyorin Pharmaceutical Co., Ltd., Japan.

\section{Materials and Methods}

\section{Drugs}

The active ingredient the test formulation (batch number FD/ 400/09; manufacturing date March, 2009) was also manufactured by Emcure Pharmaceuticals Ltd., India. The reference product Aplace $^{\circledR}$ (batch number J084, expiry date November, 2013) was manufactured by Kyorin Pharmaceutical Co., Ltd., Japan. Each film coated tablet contained troxipide equivalent to $100 \mathrm{mg}$. The study was conducted at Therapeutic Drug Monitoring (TDM) Laboratory, Mumbai, India and it was sponsored by Zuventus Healthcare Ltd., India.

\section{Study subjects}

Guidelines drawn up by the Institutional Review Board (IRB), which met the requirements of the U.S. code of Federal Regulations, the Canadian MRC guidelines and declaration of

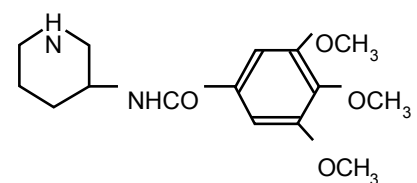

Figure 1: Chemical structure of Troxipide (Mine et al., 1991).

${ }^{*}$ Corresponding author: Dr. Bhupesh Dewan, M.B.B.S, M.D., Chief Medical Advisor, Zuventus Healthcare Ltd., 5119 'D' Wing, Oberoi Garden Estate, Chandivilli, Mumbai 400 072, Tel: +91 (0) 2230610000 / 28472823/ 24; Fax: +91 (0) 2228472828/29; E-mail: bhupesh.dewan@zuventus.com

Received February 26, 2010; Accepted April 04, 2010; Published April 04, 2010

Citation: Dewan B, Sahu N (2010) Bioequivalence Study of Troxipide Tablet Formulations. J Bioequiv Availab 2: 050-054. doi:10.4172/jbb.1000030

Copyright: $\odot 2010$ Dewan B, et al. This is an open-access article distributed under the terms of the Creative Commons Attribution License, which permits unrestricted use, distribution, and reproduction in any medium, provided the original author and source are credited.

J Bioequiv Availab

Volume 2(2): 050-054 (2010) - 050 
Citation: Dewan B, Sahu N (2010) Bioequivalence Study of Troxipide Tablet Formulations. J Bioequiv Availab 2: $050-054$. doi:10.4172/jbb. 1000030

Helsinki, Tokyo 2004 as well as the ethical norms laid down by the Indian Council of Medical Research (ICMR), New Delhi, India, 2006 were followed during the study (WMA Declaration of Helsinki, 2004; ICMR Guideline, 2006).

After approval by the Ethics Committee, 28 healthy subjects, including 4 subjects as standby to replace dropouts, were included in the study. All participants signed a written informed consent form (ICF), which had an approval of the ethics committee, after they had been informed of the nature and details of the study in a language, which they understood. Subject inclusion criteria included age between 18-45 years, non-smoker and Asian adult male of Indian origin. The exclusion criteria included history of hypersensitivity to the study product or related products, significant medical illness or conditions known to interfere with absorption, distribution, metabolism and excretion of the study drugs, significant history of medical illness like asthma, glaucoma, cardiovascular or hematological disease, significant clinical illness during the 4 weeks prior to day one of the study, maintenance therapy with any drugs, drug dependency, alcohol abuse, use of enzyme modifying drugs within 30 days prior to day one of the study or use of any systemic medications including over the counter (OTC) drugs within 14 days prior to day one of the study, subjects who had a depot injection or an implant of any drug 3 months prior to the commencement of the study, HIV or hepatitis positive subjects and subjects who donated blood $(350 \mathrm{ml})$ within last 3 months prior to the study.

\section{Study design}

It was an open labeled, randomized, two-way, two-period, twotreatment, single dose cross-over bioequivalence study, under non fed condition. Treatments were separated by a wash-out period of one week. Each subject was assigned a unique identification number.

All the subjects arrived at the study center at least 13 hours prior to the start of the study and all were given a standard dinner, which was finished at least 10 hours before dosing in each period of the study. After an overnight fasting period of 10 hours, the subjects were administered the medications as per the randomization schedule, for the test or the reference products, with $240 \mathrm{ml}$ of plain drinking water. The intake of the study formulations was closely monitored by the physician and oral cavity was checked properly to ensure completion of the administration process. Subjects were instructed to remain inclined resting for the first 2.0 hours after dosing.

No food was allowed until four hours after dosing. Water restriction was from 1 hour before till 2 hours after dosing and ad libitum thereafter. Excess fluid intake $\left(>120 \mathrm{ml} \mathrm{h}^{-1}\right)$ was not allowed. Lunch, snacks and dinner were served as per the scheduled time.

\section{Blood sampling}

Blood samples $(5 \mathrm{ml})$ were collected from an antecubital vein by an indwelling venous cannula using coded, sterile vacutainers containing ethylenediamine tetraacetic acid (EDTA) as an anticoagulant. Blood samples were obtained immediately prior to dosing (predose sampling, $0.00 \mathrm{~h}$ ) and at $0.50,1.00,1.50$, 1.75, 2.00, 2.25, 2.50, 3.00, 4.00, 6.00, 8.00, 10.00, 12.00, 16.00,
20.00, 24.00, and at 28.00 hours after dosing. Blood samples were centrifuged at $4000 \mathrm{rpm}$ (at $0-4^{\circ} \mathrm{C}$ ) for ten minutes, within ten minutes of the sample collection, to separate the plasma. The plasma was separated and stored frozen at $-20^{\circ} \mathrm{C} \pm 5^{\circ} \mathrm{C}$ until assayed.

During the study periods, all the subjects were under medical supervision. Vital signs were examined at scheduled time as per the protocol.

\section{Analytical procedure}

A validated method based on HPLC was used for determination of troxipide concentration in human plasma. Column type used was cosmosil $\mathrm{C}_{18}(150 \mathrm{~mm} \times 4.6 \mathrm{~mm}$,i.d.) $5 \mu$ and mobile phase used was $0.05 \mathrm{M}$ ammonium hydrogen orthophosphate: Methanol (70:30), $\mathrm{pH} 4.0 \pm 0.05$. Procedures of validation and acceptance criteria were based on the rules and guidelines of the $\mathrm{ICH}$ consensus Guidelines (FDA, 2001).

Aliquots of $500.00 \mu \mathrm{l}$ of drug free human plasma were taken in tubes and standard solutions of the Troxipide in HPLC grade methanol were spiked to obtain concentrations of $60.00,100.00$, $300.00,500.00,1500.00$ and $2600.00 \mathrm{ng} \mathrm{ml}^{-1}$ and the tubes were vortexed for 30 seconds, $150 \mu \mathrm{l}$ of $10 \%$ perchloric acid was added and vortexed for 30 seconds followed by addition of $5 \mathrm{ml}$ of methanol to the tubes. The tubes were sonicated for 10 minutes in ice cold water. All the tubes were shaken for 5 minutes at 10 rpm in a shaker, centrifuged for 10 minutes at $3000 \mathrm{rpm}, 4 \mathrm{ml}$ of the organic layer was aspirated and evaporated at $65^{\circ} \mathrm{C}$ until dryness under a stream of nitrogen for 10 minutes in a low volume evaporator. The residue was then reconstituted in $150 \mu \mathrm{l}$ of the mobile phase; the reconstituted residue was again centrifuged at $4000 \mathrm{rpm}$ for 10 minutes at $4^{\circ} \mathrm{C} .30 \mu \mathrm{l}$ of the clear supernatant was injected onto the HPLC system.

\section{Pharmacokinetic analysis}

The pharmacokinetic parameters were determined by non compartmental methods. Values below quantification limit $\left(<60.00 \mathrm{ng} \mathrm{ml}^{-1}\right)$ were set to zero for calculation purposes.

The maximum plasma concentration $\left(\mathrm{C}_{\max }\right)$ and the time to reach $\mathrm{C}_{\max }\left(\mathrm{t}_{\max }\right)$ were taken directly from the plasma drug concentration-time curves. The elimination rate constant $\left(\mathrm{K}_{\mathrm{el}}\right)$ was estimated by a nonlinear least square regression analysis of the individual concentrations observed as a function of time during the elimination phase. The half life of elimination $\left(t_{1 / 2}\right)$ was obtained by dividing 0.693 by $\mathrm{K}_{\mathrm{el}}$. The area under the curve (AUC) of troxipide in plasma from time zero to last quantifiable time point, $\mathrm{AUC}_{(0-\mathrm{t})}$, was calculated using the linear trapezoidal rule. The AUC from time zero to infinity, $\mathrm{AUC}_{(0-\infty)}$, was the sum of $\mathrm{AUC}_{(0-\mathrm{t})}$ and $\mathrm{C}_{\text {last }} / \mathrm{K}_{\mathrm{el}}$, where $\mathrm{C}_{\text {last }}$ is the last measurable concentration of troxipide in plasma.

The test and the reference formulations were considered to be bioequivalent if the calculated confidence intervals (C.I.s) for the log transformed ratios (test/reference) of the $\mathrm{C}_{\max }, \mathrm{AUC}_{(0-\mathrm{t})}$, and $\mathrm{AUC}_{(0-\infty)}$ were within the bioequivalence criteria range of 80.00-125.00 as established by the Central Drug Standard Control Organization (CDSCO), India; US Food and Drug Administration (US FDA) and European Medicines Evaluation Agency (EMEA). 


\section{Journal of Bioequivalence \& Bioavailability - Open Access \\ JBB/Vol.2 Issue 2}

\section{Statistical analysis}

The pharmacokinetic parameters were statistically analyzed by descriptive statistics, analysis of variance (ANOVA) test, and Schuirmann's two one sided t-test.

A certified validated WinNonlin and Statistical Analysis System (SAS) program was used for statistical evaluations of the pharmacokinetic parameters The parameters were derived individually for each subject from troxipide concentrations in plasma. The actual times of blood sampling were used for the calculation. Arithmetic means, standard deviations, standard errors and coefficients of variation for all parameters were calculated. ANOVA of AUC ${ }_{(0-t)}, \mathrm{AUC}_{(0-\infty)}$ and $\mathrm{C}_{\max }$ were subjected to a four-way ANOVA accounting for sequence, subjects, period and treatment. The statistical method for testing bioequivalence was based upon the $90 \%$ confidence interval for the ratio of the calculated means (test/reference) for the parameter under consideration. The statistical analysis (e.g. ANOVA) took into account sources of variation that can be reasonably assumed to have an effective response.

\section{Results}

Twenty seven adult males with a mean age $( \pm$ S.D. $)$ of $27.6 \pm 5.83$ years (range 20-42 years), a mean weight of $63.3 \pm 8.44$ $\mathrm{kg}$ (range $51-82 \mathrm{~kg}$ ) and a mean height of $168.4 \pm 7.00 \mathrm{~cm}$ (range $158-184 \mathrm{~cm}$ ) completed the study. As per the protocol the first 24 subjects were to be considered for the analysis. Remaining 4 subjects were to be considered as standby subjects. Subject number 09 dropped out, therefore subject number 26, carrying similar sequence of drug administration as that of subject number 09, was included for analysis. The two formulations were well tolerated by the subjects except one, who dropped out due to fever with shivering, headache and giddiness. The adverse events were unrelated to the drug. The remaining subjects continued till the end of the study.

Figure 2 shows the plots of mean serum concentrations of troxipide vs. time. Both the formulations were rapidly absorbed and detected from 0.50 hour in plasma.

Mean pharmacokinetic parameters of troxipide for the test and the reference formulation, in 24 healthy Indian subjects are presented in Table 1.

ANOVA on log transformed data failed to reveal any statistically significant differences between these parameters ( $>0.05$ ). Moreover, the sequence (or group) effect was statistically not significant in the analysis of the parameters, indicating that there was no carryover effect.

The intra-subject variation, calculated using mean square error obtained from the logarithmically transformed $\mathrm{C}_{\max }, \mathrm{AUC}_{(0-\mathrm{t})}$ and $\mathrm{AUC}_{(0-\infty)}$ values were $18.03,10.10$ and $9.98 \%$ respectively. Additionally the $90 \%$ C.I.s for the ratios of mean $\mathrm{C}_{\max }, \mathrm{AUC}_{(0-\mathrm{t})}$, and $\mathrm{AUC}_{(0-\infty)}$ were within the range of 80.00 to 125.00 (using $\log$ transformed data), meeting the regulatory criterion for

Mean Plasma Concentration vs. Time Curves

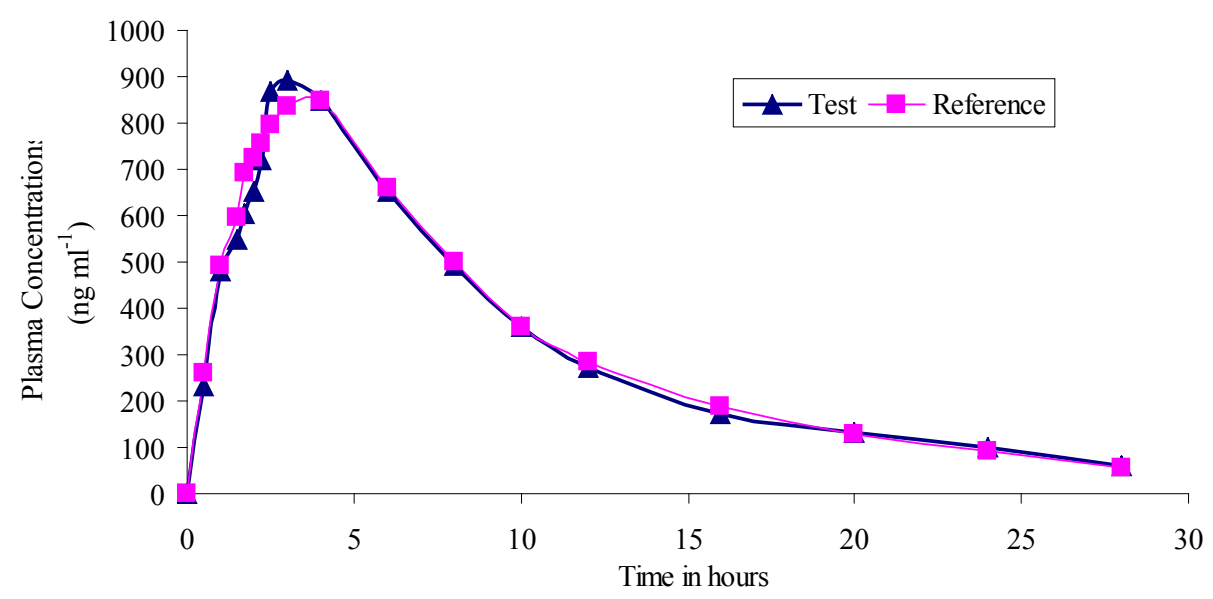

Figure 2: Mean plasma concentration vs. time curves of the test and reference tablets, each containing $100 \mathrm{mg}$ troxipide.

\begin{tabular}{|c|c|c|}
\hline Parameters & Test (mean \pm S.D.) & Reference $($ mean \pm S.D. $)$ \\
\hline $\mathrm{C}_{\max }\left(\mathrm{ng} \mathrm{ml}^{-1}\right)$ & $1052.47 \pm 254.41$ & $1039.10 \pm 301.54$ \\
\hline $\operatorname{AUC}_{(0-\mathrm{t})}\left(\mathrm{ng} \mathrm{h} \mathrm{ml^{-1 }}\right)$ & $8737.48 \pm 1545.24$ & $8850.04 \pm 1892.63$ \\
\hline $\operatorname{AUC}_{(0-\infty)}\left(\mathrm{ng} \mathrm{h} \mathrm{ml}^{-1}\right)$ & $9622.12 \pm 1692.57$ & $9695.02 \pm 2133.95$ \\
\hline $\mathbf{t}_{\max }(\mathbf{h})$ & $3.04 \pm 0.93$ & $3.07 \pm 1.39$ \\
\hline $\mathbf{K}_{\mathrm{el}}\left(\mathbf{h}^{-1}\right)$ & $0.10 \pm 0.06$ & $0.10 \pm 0.03$ \\
\hline$t_{1 / 2}(h)$ & $7.44 \pm 1.85$ & $7.24 \pm 2.10$ \\
\hline
\end{tabular}

Table 1: Mean pharmacokinetic parameters of the test and the reference formulations, each containing $100 \mathrm{mg}$ troxipide.

\begin{tabular}{|l|l|l|l|}
\hline Parameters & Ratio (Test/Reference \%) & $\begin{array}{l}\text { 90\% Confidence Interval } \\
\text { (log transformed data) }\end{array}$ & $\begin{array}{l}\text { Intrasubject Variability } \\
(\log \text { transformed data \%) }\end{array}$ \\
\hline $\mathbf{C}_{\max }$ & 102.30 & $93.62-111.79$ & 18.03 \\
\hline AUC $_{(0-1)}$ & 99.40 & $94.56-104.49$ & 10.10 \\
\hline AUC $_{(0-\infty)}$ & 100.03 & $95.21-105.09$ & 9.98 \\
\hline
\end{tabular}

Table 2: Ratio (Test/Reference), 90\% confidence interval and intra-subject variation following the administration of $100 \mathrm{mg}$ troxipide tablets. 
Citation: Dewan B, Sahu N (2010) Bioequivalence Study of Troxipide Tablet Formulations. J Bioequiv Availab 2: $050-054$. doi: $10.4172 /$ jbb. 1000030

\begin{tabular}{|c|c|c|c|c|c|c|c|c|}
\hline \multirow{2}{*}{$\begin{array}{l}\text { Subject } \\
\text { No. }\end{array}$} & \multicolumn{2}{|c|}{$\mathrm{C}_{\max }\left(\mathrm{ng} \mathrm{ml^{-1 }}\right)$} & \multicolumn{2}{|c|}{$t_{\max }(h)$} & \multicolumn{2}{|c|}{$\operatorname{AUC}_{(0-\infty)}\left(\mathrm{ng} \mathrm{h} \mathrm{ml}^{-1}\right)$} & \multicolumn{2}{|l|}{$\mathbf{t}_{1 / 2}(\mathbf{h})$} \\
\hline & $T$ & $\mathbf{R}$ & $\mathbf{T}$ & $\mathbf{R}$ & $\mathbf{T}$ & $\mathbf{R}$ & $\mathbf{T}$ & $\mathbf{R}$ \\
\hline 1 & 799.08 & 911.11 & 3.00 & 3.00 & 8753.57 & 9487.34 & 7.09 & 6.84 \\
\hline 2 & 883.78 & 887.04 & 4.00 & 4.00 & 9568.62 & 8720.77 & 6.04 & 6.88 \\
\hline 3 & 1028.91 & 1109.32 & 2.00 & 2.25 & 7690.52 & 7802.36 & 6.38 & 5.34 \\
\hline 4 & 976.03 & 1156.16 & 4.00 & 1.75 & 7503.11 & 7367.40 & 8.47 & 3.98 \\
\hline 5 & 1138.33 & 941.83 & 3.00 & 1.50 & 10829.48 & 10285.06 & 8.56 & 9.04 \\
\hline 6 & 775.67 & 784.36 & 2.50 & 4.00 & 9589.38 & 8495.11 & 7.80 & 6.31 \\
\hline 7 & 1417.71 & 1334.77 & 1.50 & 2.50 & 10526.81 & 12753.17 & 8.34 & 11.72 \\
\hline 8 & 604.82 & 994.83 & 4.00 & 4.00 & 8401.16 & 8420.81 & 9.42 & 6.64 \\
\hline 10 & 947.14 & 689.95 & 2.50 & 4.00 & 11439.25 & 8097.64 & 10.13 & 6.12 \\
\hline 11 & 1112.86 & 1384.44 & 2.50 & 3.00 & 11274.99 & 11984.79 & 6.53 & 8.70 \\
\hline 12 & 1510.66 & 1148.57 & 3.00 & 2.50 & 11019.72 & 9784.15 & 9.27 & 6.57 \\
\hline 13 & 1212.22 & 1010.86 & 3.00 & 2.50 & 12631.57 & 13055.71 & 7.96 & 10.88 \\
\hline 14 & 1151.42 & 1688.02 & 3.00 & 2.25 & 9006.08 & 12416.02 & 6.06 & 9.06 \\
\hline 15 & 1439.83 & 1088.63 & 3.00 & 1.50 & 11862.95 & 11136.76 & 8.87 & 6.86 \\
\hline 16 & 1000.87 & 948.27 & 3.00 & 1.00 & 10286.17 & 10574.18 & 7.43 & 4.72 \\
\hline 17 & 918.23 & 927.78 & 2.50 & 3.00 & 9939.87 & 9623.49 & 7.02 & 6.25 \\
\hline 18 & 1566.97 & 1387.58 & 2.50 & 2.50 & 11054.97 & 10815.13 & 7.94 & 6.44 \\
\hline 19 & 927.12 & 875.15 & 2.25 & 4.00 & 8210.91 & 7535.56 & 5.73 & 5.87 \\
\hline 20 & 1128.64 & 1164.70 & 4.00 & 4.00 & 8862.32 & 10680.57 & 5.57 & 6.66 \\
\hline 21 & 1068.02 & 1743.02 & 2.25 & 0.50 & 12008.48 & 14132.78 & 10.91 & 11.92 \\
\hline 22 & 621.66 & 554.61 & 6.00 & 4.00 & 7838.56 & 6236.41 & 5.75 & 6.87 \\
\hline 23 & 816.35 & 717.49 & 2.50 & 4.00 & 6764.54 & 7559.23 & 7.96 & 7.41 \\
\hline 24 & 1167.44 & 761.01 & 3.00 & 6.00 & 9115.66 & 9034.30 & 7.32 & 8.26 \\
\hline 26 & 1045.55 & 728.97 & 4.00 & 6.00 & 6752.09 & 6681.80 & 1.88 & 4.39 \\
\hline
\end{tabular}

Table 3: Individual pharmacokinetic parameters of troxipide $100 \mathrm{mg}$ tablets.

bioequivalence as mentioned above. Table 2 represents the ratio (test/reference), 90\% confidence interval and the intra-subject variations of the $\mathrm{C}_{\max }, \mathrm{AUC}_{(0-\mathrm{t})}$ and $\mathrm{AUC}_{(0-\infty)}$.

For overall extent of absorption, both the formulations were equivalent, with test/reference formulation ratios of both $\mathrm{AUC}_{(0-}$ t) and $\mathrm{AUC}_{(0-\infty)}$ very close to $100 \%$. Based on the plasma levels of the 24 completed subjects, the mean relative bioavailability of troxipide was $99.40 \%$ as compared with the reference.

The results of the present bioequivalence study prove that the test and the reference formulations of troxipide are bioequivalent when the same doses are administered under the experimental conditions designed for this study.

The pharmacokinetic data for each subject are illustrated in Table 3.

\section{Discussion}

This study assessed the bioequivalence of $100 \mathrm{mg}$ troxipide tablet formulation, manufactured by Emcure Pharmaceuticals Ltd., India, with Aplace ${ }^{\circledR} 100 \mathrm{mg}$ tablet of Kyorin pharmaceutical co., Ltd., Japan. This is the first bioequivalence study of troxipide in India. With its great potential use in the management of gastritis and peptic ulcers, informations on the pharmacokinetic parameters of the formulations is warranted.

Troxipide was detected in plasma from $0.05 \mathrm{~h}$ after oral administration of the test and the reference formulations, suggesting a rapid absorption of troxipide. The estimated $t_{\max }$, $\mathrm{C}_{\max }, \mathrm{t}_{1 / 2}$ of the test and the reference formulations in this study are consistent with previous investigations by Yanan et al. (2003). Moreover, the measured AUC and $\mathrm{C}_{\max }$ values following oral administration of both formulations (test and reference) were not significantly different $(\mathrm{p}>0.05)$ and maintained $90 \%$ confidence interval within 80.00-125.00 for the log transformed values, suggesting that the two formulations were bioequivalent.
Troxipide was found to be well tolerated in this bioequivalence study. This finding is consistent with previous published clinical study conducted in peptic ulcer patients by Hyeoyun, huh and Yoon describing the molecule as "very safe". In that study no patient developed side effects and there were no abnormalities in blood count, renal and liver function tests. (Hyeoyun, 1989).

In summary this study has demonstrated the bioequivalence of the $100 \mathrm{mg}$ troxipide tablet manufactured by Emcure Pharmaceuticals Ltd., India and the reference product, Aplace ${ }^{\circledR}$ manufactured by Kyorin pharmaceutical co., Ltd., Japan. Hence it can be concluded that the two formulations can be used interchangeably in clinical settings.

\section{References}

1. FDA (2001) Guidance for industry: bioanalytical method validation. U.S. Department of Health and human services. Food and drug admin-istration, Center for Drug Evaluation and Research: Rockville 1-22. » CrossRef » PubMed » Google Scholar

2. Hyeoyun, Yoon (1989) Clinical Trial of Troxipide in Peptic Ulcer. Modern Medicine 32: 125-131. » CrossRef » PubMed » Google Scholar

3. ICMR Guidelines (2006) Ethical Guidelines For Biomedical Research On Human Participants, Indian Council of Medical Research, New Delhi 1-111. »CrossRef » PubMed » Google Scholar

4. Kusugami K, Ina K, Hosokawa T, Kobayashi F, Kusajima H, et al. (2000) Troxipide, a novel antiulcer compound, has inhibitory effects on human neutrophil migration and activation induced by various stimulants. Dig Liver Dis 32: 305-11. »CrossRef » PubMed » Google Scholar

5. Mine T, Kataoka A, Fujisaki J, Sato E, Yasuda H, et al. (1991) Effects of Cimetidine and Troxipide on gastric mucosal prostaglandin synthesis in patients with chronic gastric ulcer. Curr Ther Res 50: 878-886. »CrossRef » PubMed » Google Scholar

6. Momo K, Hoshina K, Ishibashi Y, Saito T (1994) Preventive effects of troxipide on a newly developed model of acute gastric mucosal lesion (AGML) induced by ischemia/reperfusion plus ammonia in the rat. Nippon Yakurigaku Zasshi 104: 313-2. »CrossRef » PubMed » Google Scholar 


\section{Journal of Bioequivalence \& Bioavailability - Open Access}

\section{www.omicsonline.org}

7. Prescribing information, Aplace ${ }^{\circledR}$, Kyorin Pharmaceutical Co.,Ltd, 2010. »CrossRef » PubMed » Google Scholar

8. Wang J, Zhang L, Fang Z, Fan A, Wang Y (1993) The pharmacodynamics of troxipide on experimental gastric ulcers in rats. Hua Xi Yi Ke Da Xue Xue Bao 24: 313-6. »CrossRef » PubMed » Google Scholar

9. WMA Declaration of Helsinki (2004) Ethical Principles for Medical Research

\section{JBB/Vol.2 Issue 2}

Involving Human Subjects. World Medical Association General assaembly Tokyo. »CrossRef » PubMed » Google Scholar

10. Yanan Z, Furong Q, Weijia W, Sun H, Min D, et al. (2003) Relative bioavailability and bioequivalence of troxipide capsule in healthy volunteers after a single oral administration. J Clin Pharmacol 19. » CrossRef » PubMed » Google Scholar 